Sheridan College

SOURCE: Sheridan Institutional Repository

$7-8-2020$

\title{
Transcending Lockdown: Fostering Student Imagination through Computer-Supported Collaborative Learning and Creativity in Engineering Design Courses
}

\author{
E. Martin Nolan \\ University of Toronto
}

Follow this and additional works at: https://source.sheridancollege.ca/fhass_creative_humanities

Part of the Computer Engineering Commons

\section{SOURCE Citation}

Nolan, E. Martin, "Transcending Lockdown: Fostering Student Imagination through Computer-Supported Collaborative Learning and Creativity in Engineering Design Courses" (2020). Creative Humanities Special Issues. 5.

https://source.sheridancollege.ca/fhass_creative_humanities/5

\section{(c) (1) (9)}

This work is licensed under a Creative Commons Attribution-Noncommercial-No Derivative Works 4.0 License. This Article is brought to you for free and open access by the Faculty of Humanities \& Social Sciences (FHASS) at SOURCE: Sheridan Institutional Repository. It has been accepted for inclusion in Creative Humanities Special Issues by an authorized administrator of SOURCE: Sheridan Institutional Repository. For more information, please contact source@sheridancollege.ca. 


\title{
TRANSCENDING LOCKDOWN:
} FOSTERING STUDENT IMAGINATION THROUGH COMPUTER-SUPPORTED COLLABORATIVE LEARNING AND CREATIVITY IN ENGINEERING DESIGN COURSES

\section{E Martin Nolan}

\begin{abstract}
Engineering design and communication courses are typically dynamic, active learning spaces that bring together a complex array of knowledge and skills. Their ambiguous nature has allowed, often contentiously, subjects such as language and communication, the arts, the humanities and the social sciences to enter the discourse of engineering in a newly meaningful way. This paper considers this development in the context of the COVID-19 pandemic, and in particular how the creativity and imagination required to succeed in engineering design might be cultivated in emergency distance learning. I consider a plethora of sources for guidance, with a special interest in how language and communication facilitates collaborative learning, creativity, and intersubjectivity and how that mediation is further mediated by educational technology in distance learning. I focus on the challenges faced, and the resulting importance of training for both instructors and students. Finally, I argue that despite our difficult circumstances, we should aim to encourage our students to exercise their imaginations, both independently and collaboratively, through our selection, framing and facilitation of team design projects during the pandemic.
\end{abstract}

\section{Keyword}

Engineering Design; Engineering Communication; Creativity; Imagination; Intersubjectivity; Collaborative Learning; Pedagogy; CSCL; CALL; Emergency Online Education; Transdisciplinary

\section{Author Affiliation}

E Martin Nolan, Professor of Engineering Communication, Engineering Communication Program (ECP) and Institute for Studies In Transdisciplinary Engineering Education and Practice (ISTEP), University of Toronto (emartin. nolan@utoronto.ca) Nolan, E Martin. "Transcending Lockdown: Fostering Student Imagination through Computer-Supported Collaborative Learning and Creativity in 


\section{Engineering Design Courses."}

Online Ahead of Print | University of Toronto Quarterly | Special Issue on The Creative Humanities https://source.sheridancollege.ca/fhass_creative_humanities/5 


\title{
TRANSCENDING LOCKDOWN:
} FOSTERING STUDENT IMAGINATION THROUGH COMPUTER-SUPPORTED COLLABORATIVE LEARNING AND CREATIVITY IN ENGINEERING DESIGN COURSES

\author{
E Martin Nolan
}

Introduction

We find ourselves in the midst of a profound global turning point-one that deserves our full attention. This is especially apparent in the realm of engineering design, given the central role that practice has played, and will continue to play, amid the myriad of crises the world currently faces. In this essay, I will discuss the role of engineering design and communication courses in this age of crisis. I will also review the current state of engineering design and communication education and consider the impacts on course design of the Covid-19 pandemic and the resulting move to emergency online instruction. Finally, I will recommend criteria for selecting an engineering design project, given the unique circumstances of this novel semester. Below, I briefly preview the issues covered in this article.

\section{Critical Issues}

Everything is falling apart, and the centre's hold hesitates. I wrote that the day after the remnants of Tropical Storm Cristobal broke up over the American Midwest, scattering the last of its power in wind and rain across Wisconsin and Michigan. Meteorologist Chris Dolce reported that this was only the third tropical depression on record to reach Wisconsin. That is only one of the five "unusual things" Dolce listed about the 2020 hurricane season, as of June 10. The others included the emergence of two named storms in May, before hurricane season officially begins. This year also saw the earliest recorded arrival of the third named storm of hurricane season.

Dolce points out that such early activity does not necessarily indicate a more active season as a whole, but the unusually fast start indicates further evidence of a growing trend of troubling news on the climate crisis front. Fifteen days later, temperatures in the Russian Arctic reached 38 degrees Celsius, a record high that is a part of a rapid warming trend that is causing increased forest fires and melting permafrost in the region. These are just two 
examples among the many I could draw from and they represent just the tip of the (melting) iceberg. Add COVID-19 to the mix - with all its accompanying death, suffering, political instability, and economic chaos-and it is easy to find cause for anxiety over the future, and at the grandest scales imaginable. The question becomes: can we imagine, really, the crises we face and is it plausible that we might imagine our way out of them?

Meanwhile, I find myself on a team preparing a first-year engineering design and communication course for the Fall 2020 term. It is very difficult to separate these clusters of crises, and their potential range of failures and solutions, from the content and goals of such a course. A practical, problemsolving-oriented course will almost inevitably take in some part of the myriad of problems alluded to above. But here's the rub: in what manner and to what degree the course embraces such topics, we cannot easily say, because it is far from simple to bring the ongoing dynamics of a suddenly more unstable world into the classroom, which necessitates a certain level of stability in order to be effective, consistent, and fair.

To varying degrees in different design courses, this tension is worked out through assigned design tasks. In our case, we must design a fall project for the students to address, in teams, through engineering design processes. Each year's project is unique and poses different kinds of challenges to the student teams, the teaching team, staff, and other stakeholders. This project is central to the students' learning experience, and what follows is an examination of what we should account for in deciding how we might choose this year's project, especially given the circumstances imposed by the pandemic. That choice, as we will see, depends on and impacts our delivery of core course learning objectives, particularly those concerned with fostering creativity and, I will argue, imagination.

\section{Teaching Engineering Design and Communication Online}

That brings me to another major challenge this fall, and likely well beyond: this hands-on, active-learning and team-based course, which requires collaborative creativity and robust communication, will be delivered online. This circumstance completely alters the social learning space the course was designed around. Much of the potential to foster the intersubjectivity and social connection-so essential to student learning in such courses-will be lost in this transition. We are not hopeless to recover at least some of what it is lost-and there are advantages to teaching online, too-but it takes careful consideration to ensure that happens. Therefore, the second part of this essay will consider how we might facilitate collaborative creativity, and the communication it depends on, online.

\section{Determining a Design Project for Fall 2020}

Online Ahead of Print | University of Toronto Quarterly | Special Issue on The Creative Humanities https://source.sheridancollege.ca/fhass_creative_humanities/5 
The imposition of online learning, in turn, directly bears on the selection of the fall design project, because what is reasonable to expect from student teams working online should determine the proper level of ambitiousness for the project. There is a case to be made for a project scaled back in its ambition. A relatively simple project could, theoretically, avoid pushing undue complexity on a student cohort that is already heavily burdened by the circumstances imposed by the pandemic. Still, I will explore the possibilities of the opposite approach, to consider the potential for a relatively complex project that requires the students to more robustly exercise their imaginations. Ultimately, I will argue for a flexible project that might require a relatively simple design task, but also allows students to extend their ambitions if that possibility emerges.

In the end, while we are limited by the constraints imposed by quarantine measures, those very constraints - and the loneliness and isolation they enforce-also add extra motivation to encourage student imagination, for what has proven better at providing escape from isolation than the human capacity to imagine? And if we step back to consider the global crises that predate, are intertwined with, and will outlast the pandemic, engaging students' imagination becomes an even more urgent need, because the only way we can begin to grasp our historical moment in all its resounding complexity is through profound acts of the imagination. This final point relates to a subject I will touch on in more depth below: the role of language, the arts, and the humanities in engineering design courses. That role, as we shall see, is related to the emerging centrality of design in engineering education, culture, and practice. Design, especially in an era like our own, inherently involves the designer embracing ambiguity, and a need to creatively meet that ambiguity through problem-solving.

That role for ambiguity represents a shift within engineering tradition, which had earlier tended toward analytical certainty rather than the creative solving of relatively open design problems and opportunities. In this process, design has caused engineering to look outside of itself-if sometimes grudgingly and slowly - to integrate the tools needed to cultivate the necessary creativity and imagination in student engineers. This larger cultural shift will serve as a backdrop to the more local, and immediately practical, focus with which this essay will conclude.

\section{Part 1: Teaching Engineering Design and Communication in a White Water World}

Imagination, Creativity and Design in an Engineered World

Engineers have been essential to the development of the modern world, and without a doubt they will play a similar role in whatever world is to

Online Ahead of Print | University of Toronto Quarterly | Special Issue on The Creative Humanities https://source.sheridancollege.ca/fhass_creative_humanities/5 
come. In "The True Grand Challenge for Engineering: Self-Knowledge," Carl Mitcham, in an allusion to Percy Shelly's claim for poets, calls engineers "the unacknowledged legislators of the world" who determine much of our "engineered lives." Yet, despite the "role of engineering in transforming our world...engineering makes almost no effort to give engineers-or any of the rest of us - the tools to reflect on themselves and their world-transforming enterprise." Mitcham argues that education is the "natural site" for such "critical reflection on our engineered lives" (1-2). Some may question the strength of these claims, and rightly point out that these issues are the subject of a lively debate within engineering education, and in particular engineering design education. However, that critical reflection needs to be taught should not be in question. And, as I will argue, such potentially worldtransforming criticality can only be done with the aid of student engineers' individual and, perhaps more importantly, collective imaginations. From that perspective, it is indefensible to not engage student engineers' imagination.

However that may come to be, we can say for sure that language use will be central to it. Collaborative learning, creativity, and communication are now well established cornerstones within engineering design practice and education. Due to the complex nature of their work, engineers regularly work in teams, making the ability to be "on the same page"-or, to reach intersubjectivity - essential to their success. The now-well-established tradition of teamwork-based engineering design and communication courses stands as strong acknowledgement of the essential role of collaboration and the language use that facilitates it.

Major questions emerge here: how is the collaboration framed? How much agency and creative and imaginative freedom are students offered? What is the role of ambiguity in this process, and how are students guided in confronting that ambiguity? Finally, what role does creativity and the imagination ultimately play in this process?

\section{The Pragmatic Imagination}

In Design Unbound (Vols. 7-2), Ann M. Pendleton-Jullian and John Seely Brown set out to detach design thinking from traditional disciplinary boundaries and categories of practice. This is in reaction to the modern world's increased ambiguity and complexity, or what they claim to be the development of "a white water world," which "is rapidly changing, increasingly interconnected, and where, because of this increasing interconnectivity, everything is more contingent on everything else happening around itmuch more so than ever before." Meeting such challenges, the authors claim, requires "understanding how to skill up for dynamic contexts in which things change and emerge without respite." Such an understanding requires more than just new skills and tools, but also "a different way of being in the world" 
$(\mathrm{l}: \mathrm{VI})$. This new mode of being —and this is crucial—will "require imagination and tools that instrumentalize the imagination" (1: IX).

Design Unbound (Volume 1) claims that while the last century was defined by "making things...the twenty-first century must be the era of the imagination" (51). The authors define imagination as "a powerful mental tool that is nurtured as the mind translates experiences in uniquely personal ways, and then constructs connections through the simultaneity and entanglement of images" (145). In Volume 2, the authors claim that the imagination "is given permission to play without pragmatic intent" (387). This is opposed to creativity, which involves the "making of a product" (388). Design Unbound brings imagination and creativity together to form what they call the "pragmatic imagination," which "sets the imagination in motion, scaffolds its emergence, and then instrumentalizes its products to accomplish real world things" (1: 50). This "paradoxical concept" of pragmatism combined with imagination offers, the authors claim, "a new role for the imaginationan imagination entangled with action and put to purpose" (1: 51). Yet, despite this attempt to rescue the concept of imagination from its state of being "too often associated with pure artistry, willfulness, or inspiration", the authors still claim that "imagination cannot be learned" (1: 145). This poses a potential problem for us, for how do we demand of our students a capacity that cannot be learned?

However, the authors also claim that while imagination is not a trainable skill, it is "an ability...natural or acquired" and that associated activities can be "scaffolded by the wealth of other mental activities that can be defined as skills" (1: 145). The skills listed_-"mental skills of reasoning, analysis, probing; hand/body skills of action and work; and the capacity to do these quickly and simultaneously" (1: 147) —are key to linking the "free play" of imagination to producing actual change in the world. The skill of empathy, however, emerges as key. The authors expand the typical definition of empathy from "the ability to identify with another person", to "the ability to engage context, either embedded in it, or as if embedded in it" and to "understand context from an internal frame of reference". While, much like imagination, "empathy can be natural", the authors claim that "it is also a skill that one can intentionally develop or nurture" (1: 148-9). Ah! So, it is not just training that we need, but also practice, development, and cultivation. We might train instructors and students, then, in order to promote that ongoing learning.

\section{Empathy, Imagination, and Dialogue}

Karen Krasney takes a Bakhtinian route to a similar concept of the connection between empathy and imagination, arguing that Bakhtin and others in the western tradition have over-emphasized the role of language to the detriment of the (often non-linear) images that dominate 
the human imagination, claiming that "embodied cognition holds that the active manipulation of existing images is fundamental to the imaginative projecting of events and empathetic identification" (190). Krasney describes the imagination-enabled skill of empathy as a "form of intentionality in faceto-face intersubjective encounters" (191). This imaginative ability is aided, mediated, and influenced by language, but also depends on non-linguistic imagistic thinking. Krasney aligns here with the authors of Design Unbound through her appreciation and reframing of one of Bakhtin's central concepts. Krasney argues that Bakhtin undervalued the image in favour of the word. She does not deny the magic Bakhtin, like Vygostky, attributes to the word, but she does reassert the importance of the image in the imagination (which does contain most of the word, "image").

A clear trend is beginning to emerge: an acknowledgement that human knowledge is shared knowledge, and that the imagination is key to sharing knowledge. The skill of empathy that Pendleton-Jullian and Brown see as necessary to the pragmatic imagination, Krasney sees as "the capacity to interpret the other's state of mind in the reciprocal relation between self and other, speaker and addressee," which "accounts for the anticipatory movement in Bakhtinian addressivity" (191). In both cases, the imagination is essential to understanding others, understanding with others, understanding contexts and to gaining the experience and knowledge that intersubjectivity makes possible. And, given the complexity of our current world, such linking together of minds, as engineering design has long known, is absolutely essential.

However, we have not yet seen how that might be taught or cultivated through training, and in online environments. There are good reasons for skepticism on this account. Krasney ends her essay with a look towards "the unqualifiability of the brain's potential for diversity and variability," leading her to a rather celebratory reference to the imagination's "open-ended" nature (194). For literary scholars, such unknowability and ambiguity quite rightly provides for endless literary interest. For teachers of engineering design, unknowability, if transferred to students, might seem a waking nightmare. But, again, we are not helpless. In fact, the challenge is not to eliminate ambiguity and confusion-for that is the state of the world-but to meet it and to offer students the tools to allow them to do the same. We all have to learn to roll with this.

\section{Training for Creativity}

Lopata et al., like Pendleton-Jullian and Brown, claim that creativity and other imagination-related skills can be taught. Measuring creative skills among jazz musicians with different levels of institutional training, the authors found that musicians with more formal training produced "higher quality improvised

Online Ahead of Print | University of Toronto Quarterly | Special Issue on The Creative Humanities https://source.sheridancollege.ca/fhass_creative_humanities/5 
performances that are rated as being better overall by domain experts" (255). While acknowledging uncertainties in their study - which relied on EEG measurements as well as expert opinion-and cautioning against generalizing results to "other types of creative people," including "engineers," Lopata et al. are still clear in their claim that "creativity can be nurtured through training" and that "immersion in the creative state has high cultural and economic value because it yields higher quality products" (255).

The focus on products aligns with Pendleton-Jullian and Brown's definition of creativity. Interestingly, Lopata also refers to the artists in their study "imagining playing the melody," and "imagining improvising freely" as separate categories from the creative (product-making) acts of "actual playback" and "actual improvisation" (p. 250), suggesting a similar differentiation of creativity from imagination as is suggested by Design Unbound. Lopata et al. credit the achievement of the higher-level performers to those musicians' experience, as their training allows them to "become set in processing musical ideas deliberately rather than spontaneously" (255). There is obviously no simple one-to-one comparison to be made between improvising jazz musicians and engineering design students, but the evidence seems clear that the deliberate transfer of the imagination into creative endeavor depends on individual experience and is teachable, trainable and practicable. What that teaching, training and practice might entail for students and instructors in an emergency online teaching environment is covered below. Despite what we know already about online teaching, the coming terms will be an ongoing lesson, one that began when COVID-19 arrived in earnest.

\section{Part II: Teaching Engineering Design and Communication Online Computer Supported Collaborative Learning}

It is likely both too late and too early for most educational institutions making massive shifts to online education in the Fall of 2020. It is too late, as Rush et al. have shown, because properly shifting courses-especially large ones (not to mention entire universities) - from face-to-face to online environments requires more than just one summer. It is too early because educational technology is still immature. Seen through the lens of Carlota Perez's work on techno-economic paradigm shifts, the innovations brought on by the current technological revolution-embodied by information technology and the internet-has unevenly diffused, or established itself, into the higher education sector. While the Pandemic is spurring a surge in that diffusion, the "organizational inertia" (198) common to public institutions means that the educational technology we have to work with is still, in important ways, in a developmental phase. 
The more urgent point for us, however, is that the practices surrounding existing technologies we are planning to use are also in a formative stage. That is where our agency as instructors comes into play, specifically through course design and training. Timothy Koschmann might agree. Over two decades ago, he identified a paradigm shift spurred on, in part, by the study of Computer Supported Collaborative Learning (CSCL). That shift is from a "transmission model of instruction" (8) to "a commitment to learning through doing, the engagement of learners in the cooperative (as opposed to competitive) pursuit of knowledge, the transitioning of the instructor's role from authority and chief source of information to facilitator and resource guide" (13). This transition toward more active and social learning techniques mirrors the development of similar teaching methods that are also now well established in engineering design pedagogy.

Despite such establishment, development and debate continues, and the recent move online poses unique challenges and opportunities. CSCL provides insights into how those might be met. Stahl et al. argue that "collaboration, computer mediation and distance education has problematized the very notion of learning and called into question prevailing assumptions about how to study it" (1). One major resulting theoretical shift intrinsic to this current investigation is in the difference between "cooperative" and "collaborative" learning, with the former describing the work of an individual that is then combined into a final product, while the latter describes "learning that occurs socially as the collaborative construction of knowledge" and "social sharing of group meanings" (3). CSCL theory describes important practices surrounding educational technology geared to enable such learning. Stahl emphasizes that "the software is designed to support, not replace, these human, group processes" (7). As these occur in socially-constructed educational settings, "a desired form of practice becomes such through the organized actions of its inhabitants" (10). For us teaching inhabitants of online environments intended to spur collaborative learning and creativity in the Fall of 2020, that means we must consider how we use the tools at our disposal to foster "intersubjective learning" and "group cognition" (11) in a way that allows for creativity and imagination to thrive.

\section{The Central Role of Language in CSCL}

More recently, Stahl described a group of math students succeeding in a CSCL task:

By adopting specific sequences of group practices, the team learns how to collaborate, to manipulate technological affordances, to engage in collaborative dynamic-geometry problem solving and to enter into mathematical discourse. Displayed in the team interaction, we can see group cognition in action as a specific form of intersubjectivity ("From Intersubjectivity" 20).

Online Ahead of Print | University of Toronto Quarterly | Special Issue on The Creative Humanities https://source.sheridancollege.ca/fhass_creative_humanities/5 
While the activity described here is different than what occurs in engineering design teams, this description can serve as an exemplar of the kind of group cognition and intersubjectivity that are prerequisites to the success of any group learning task in computer-mediated environments. Stahl connects this group learning to the individual level through the concept of "personal zones of proximal development," which allow for "one student [to] contribut[e] a skill or insight from their individual perspective or developmental zone into the group work-usually in response to what another student did or tried to do." This creates a feedback loop in which differences in individual knowledge contribute to group meaning making, and vice-versa: "first, the group learns a skill or insight and through that, each of the other individuals learns it" (20).

Such positive, dynamic interplay is impossible if a group experiences communication breakdown-and, indeed, such breakdowns are all too common in engineering design, often with disastrous consequences. Invoking Vygotsky, Heidegger, and Tomasello, Stahl confirms that "in the mixing pot of group discourse, phrases evoke each other and thereby generate creative ideas," but only if "competent language users...speak and understand the phrases." Stahl goes so far as to claim that "group cognition and its associated intersubjectivity can be conceived in primarily linguistic, rather than mental, terms" (21).

\section{The Role of Language in Engineering Design}

In the context of engineering design, Dym echoes Stahl when he claims that-in addition to the traditionally accepted notion of mathematics as "the language of engineering"-designers "use a lot of words...often in a very structured way" and "that there are many languages of design" (144). Geisler and Lewis discusses how engineers "use creativity [and] capacity for imagination" to "remake the world" and argues for the primacy of "the role that language plays in the process of remaking the world" (317). Even the most technical, and seemingly non-linguistic, aspects of engineering design-such as building prototypes, testing, and estimation-rely on language, just as Stahl shows with the mathematics students above.

We can identify two major roles of language for teams in engineering design courses. First, it serves interpersonal communication through collaborative learning and creativity. Geisler and Lewis state that "increasingly, design is... collaborative" because "current design requires more knowledge than any single individual" can possess (319). Thus, language is required for teams to successfully collaborate when solving problems through the design processes that form the basis for their work. These processes-which include the creation of engineering requirements, investigation into stakeholders and environmental concerns, ideation, concept selection and development, prototyping, testing and more-are thus central to the learning objectives of 
design courses. These processes might be broadly said to serve engineers, as well as student engineers, by providing structure to ambiguity by giving design teams a set of methods through which to transform open-ended problems into potential solutions that can be measured with certainty.

Geisler and Lewis frame the relationship between ambiguity and certainty in engineering design and communication courses as a core tension that such courses aim to address. On the one hand, engineers "tend to believe that the best language is language that is transparently clear." On the other hand, design problems are often anything but certain, and that is reflected in "design assignments [which], like most design texts, have an inherent ambiguity that often serves the purpose of richly affording, but not forcing, design choices" to the teams solving them. A major goal of engineering design and the courses that teach it, then, is to train students to move from the ambiguity of real-world design problems to the certainty of verified and validated engineering design solutions. As Geisler and Lewis point out, this process involves the use of non-linear texts and communication processes, in order to forge some order out of complexity.

The second role for language is that it is essential to engineering documentation, presentations, and other communicative deliverables. This role for language stands in contrast to the one described above. While language in a design process, such as ideation, serves partly to acknowledge the ambiguity of a design problem as it is, the language of engineering deliverables is far more certain. That is, while the outcome of engineering processes should be as clear and certain as possible, the path engineers take there should be open to new information, such as that brought about by an embrace of ambiguity.

Here, I focus primarily on the first of those two uses of languageinterpersonal communication through collaborative learning and creativityfor two reasons. First, the practical goals and skills involved in engineering communication deliverables deserve, have been and will continue to receive attention. True, there is plenty more to be said about issues such as collaborative writing practices, especially online. But, for now, I want to shift the focus away from deliverables. In Mitcham's words, "engineering faculty (administrators even more so) have a tendency" to consider "humanities" subjects like language use, "as justified only insofar as they provide communication skills" (3). Such "instrumental value" (4), while important, does a disservice to the other role described above for language: as essential to all collaborative learning and creativity.

Therefore, despite this scoping out of communicative deliverables, we can still frame engineering design courses as significantly language-based, and thus turn to the literature on language acquisition for guidance in how

Online Ahead of Print | University of Toronto Quarterly | Special Issue on The Creative Humanities https://source.sheridancollege.ca/fhass_creative_humanities/5 
to establish best practices during this emergency shift to online learning. I should note, first, that issues around second language acquisition and English for special purposes in engineering design courses are prominent enough to deserve a level of consideration that I do not have room for here, but even so, the principles evoked in such a consideration would apply to some degree to all students in such courses. That is because, as Stahl points out, successful collaborative learning requires "competent language users (21)" and in specialized subjects such as engineering design, even talented and well-versed language users will require some training to learn the specific meanings and uses of language within this new context. Therefore, while language experience differences will inevitably occur within given teams, and deserve their own focus, there is still much to be learned from the rich literature that has emerged around language acquisition in online environments.

\section{On Language Training: Transferring the Lessons of Computer Assisted Language Learning (CALL) to Engineering Design and Communication Courses}

Many of the lessons drawn from the literature on SLA align with observations made so far. Stahl et. al. claim that "online teaching requires at least as much effort by human teachers as classroom teaching" (2). Much of that effort is spent in the technical and pedagogical training needed to teach effectively online. In discussing task-based-language teaching, Lai and Li identify a need for "enhancing teachers' understanding of the pedagogical values of the various tools in technological environments and their communicative and intercultural competency, enabling them to serve as effective trainers and facilitators for the learners" (511). Haines finds such training lacking, arguing that teachers need to be able to recognize educational technology's "affordances," or "the potential that teachers perceive in a particular technology tool that will support learning and teaching activities in their educational contexts" (166).

Haines recognizes this as a problem for both pre-service and in-service teachers, and connects it with ongoing teacher learning. "Perceptions of learning affordance" Haines writes, "develop over time and through experimenting with using new tools in the classroom" (173), meaning that training, in a sense, never ends. That is in keeping with a general ongoing tendency toward life-long learning in higher education, which itself reflects the increased pace of technological change, but it is also because teachers and their contexts differ: "perceptions will differ between individual teachers in relation to the learning actions that they see as important in their classrooms" (173). Despite this need for life-long learning, however, such training can, and should, be embedded early in a teacher's career. As Haines 
argues, "new teachers can be trained to look for learning affordances, which may mean quicker perceptions of affordances of future technologies" (175).

The challenge that emerges for teachers of CSCL-to learn to identify effective affordances in available tools in order to foster effective collaboration among student teams-is directly connected to the challenges students face in learning to learn in these online environments. Reinders and White discuss this in terms of the development of learner autonomy within collaborative processes, in a manner that aligns with Stahl's notion that while group learning is collaborative, it is simultaneously individual: "the responsibility learners were required to assume for their own learning and for the nature of the learning was seen as the product of an interdependent, collaborative process" (148). Hubbard sees that process as a two-way street in which traditional notions of teachers and students must give way to allow for a dynamic interplay between two parties that are, in different ways, both learners. To that end, he urges teachers to "experience CALL yourself" (166), because "teachers who have engaged in language learning using technology bring an added dimension to CALL that is missing from those who rely solely on the literature" (169). At the same time, if "learners are to take responsibility for their own learning," then teachers should "give learners teacher training" (166) because "training of this sort could have a long-term effect on increasing autonomy" (169).

Elsewhere, Hubbard, and loannou-Georgiou label this approach as "teaching reflectively," as opposed to the notion, borrowed from Brookfield, of "teaching innocently," which describes teaching practices that "do not challenge the assumptions underlying their teaching actions" (13). In light of our current pandemic-induced uncertainty, this notion of "reflection-for-action," in which teachers take on "a proactive mindset, reflecting on knowledge and experience of the technology, the learning objectives and the teaching situation to craft a more efficient and effective language learning experience" seems entirely apt (13). Teaching and learning in this kind of active, ongoing manner was already a useful concept, and it becomes only more so in this time of great uncertainty and change.

\section{Building Trust to Foster Creativity and Imagination in CSCL}

Another key element in the creation of online learning spaces is the creation of a sense of community and trust that will allow creativity and imagination to flourish. Rovai defines a "learner community" as "consisting of four related dimensions: spirit, trust, interaction, and commonality of learning expectations and goals" (4). Senior builds on that work, and that of others, to argue that "unless the community is nurtured" (144), teachers will be unable to create the necessary "connectivity" (139) and "rapport" (141) in their online environments. 
Echoing Krasny, Bettoni et al. builds off Schwartz to argue that the reception of communication in small groups is even more important than its production: "the effort of an individual student to understand other colleagues constitutes the real driving force of collaborative learning." Given this importance, they test and discuss a system and platform-which they call "electronic Collaborative idea Cultivation", or "eCiC"—-designed to guard against the common occurrence that, in a small group setting, an individual students' ideas gets lost "in a sea of words" instead of "being taken seriously, kept alive and recognized for its value." Given this need for students to be able to capture, hold and "cultivate" the ideas of individuals in their group, they suggest that online creativity should be "guided by the objective of promoting a sense of community (3926)" that will allow for intersubjectivity to emerge.

Tools and training are essential to consider in this effort, and much of the research in this area is focused on those two elements. For instance, Bhagwatwar et al. study the use of "contextual priming objects" in virtual hyper-immersive learning environments, while Ez-zaouia et al. study the potential for a tool called "Emodash" to allow instructors working with small telecollaboration groups to monitor and track students' emotional states. The collaboration tool discussed by Bettoni et al. is designed to foster such community and intersubjectivity. Link et al., meanwhile, consider the use of "anchored discussion" to foster creativity in online groups. While the specific uses of the tools referenced above may not be directly applicable to our own situations (unless we happen to be using these tools or ones like them), it is notable that they all share a goal of fostering community and creativity in online spaces, and thereby contribute to the vital process of transferring what we have learned about online learning to the related, but different, situation of online creativity, where trust is also extremely important. Referring to Voight and Bergener, Link et al. suggest that trust plays a key role in "the development of group creativity support systems" in fostering group creativity online (33).

There is more to be said for how tools and training can be used to foster such trusting environments online. For now, we can conclude that intensive and effective training-for instructors and students (with instructors passing their training down to students) - will be needed if we wish to see trust and community cultivated this fall. Once we determine to what extent such training is possible, and the potential learning affordances it will, in turn, make possible for students, we can begin to consider the extent to which the fall project might be designed to activate students' imaginations. Of course, such projections are only possible through the utilization of our own collective-and informed-imagination. 
Part III: Deploying the Imagination in the Fall 2020 Term: Striking the Balance

We now return to our current context, in which we must quickly develop and deploy a plan to foster collaborative learning and creativity in an online setting. The form of creativity that occurs in an engineering design course is multi-dimensional, complex, and difficult to teach in the most ideal settings. The online environment will pose additional challenges to us. Yet, as we have seen, it is possible to foster creativity and scaffold imagination, and it is also possible for student teams to reach a meaningful level of intersubjectivity working online. How well that all comes together this fall should be the subject of close attention going forward. That brings me back to the concern stated at the top of this investigation: what kind of design project do we assign to the engineering design student teams in the first fall of the COVID-19 pandemic?

The prudent answer goes something like: "build a better mousetrap." There is a compelling argument for this approach. While I have pontificated here upon the glories of creativity and the imagination, an engineer might correctly point out that engineering design is based on mastering processes, most of which are rather mundane and yield similarly mundane, but utterly important, products. Few will feel great excitement over the details around the development of a slightly-more-elastic strap, but most will agree that it is good for engineers to work incrementally towards that if it results in increased safety for people in car accidents. An approach designed around such seemingly-dull concerns is not uncommon. Lindsay describes a course project involving mousetraps, but with a twist. The course asked some student teams to design and build popsicle stick bridges that must accommodate the mousetrap-powered cars designed and built by other teams. The intention here is for a relatively simple project that can serve as a straight-forward experience of the design process and the very important links between designing and building-Design Unbound would label the latter a "skill associated with the hand" (1: 145).

There is much value in such simplicity, but also much potential lost. Such an approach could reasonably be thought to allow for an easier gain of intersubjectivity between teammates, because they do not need to stretch their collective imaginations very far to reach each other. It also-and this is a very big gain-allows the design process to be reduced to an easily understandable size and shape. The link between designing and building is also key, and speaks potentially to a fascinating ambiguity, however contained, between the imagined design and the physical prototype. However, what is lost in such a scenario is significant. Such a deliberate move away from the out-there-ness of the world eliminates an opportunity to reinforce the fact that, no matter how aware they are of their own 
imaginations, engineers carry out the imagination of the world they inherit and build.

There are inherited cultural reasons for engineering departments to play it safe right now, too. Goldman and Johnston et al. have described what they call engineering's "social captivity," arguing that engineers are thought to carry out the mandates of power, be that corporate, nationalist, or otherwise. The profession and practice, the argument goes, is one of makers who carry out, through creative processes, the imaginative impulses of others. Pendleton-Jullian and Brown are aware of this, as borne out by students, when they write that "the greatest difficulty in teaching design to engineering students is the students' insistence on constraints and answers that are concrete, and methods and procedures that are systematic with relatively foreseeable results" (1: 75). A mousetrap-level design challenge would play to this desire for certainty, and likely even more so during a pandemic. That attitude on the part of students is not a guarantee (what is these days?), but perhaps that could be turned into a useful approach. Perhaps, also, we might engage the students' imagination elsewhere in the curriculum.

In any case, despite whatever barriers exist, engineering design education has progressed too far, and too fast, to avoid taking up this imaginative mantle in some way, and design is the natural place for student engineers to develop and negotiate their agency, creativity, and imagination. While Mitcham is quoted above griping about a continued shunning of the humanities, he has also written a book, with Muñoz, called Humanitarian Engineering, in which the authors explicitly call for a humanities-influenced form of engineering practice, defined as "the artful drawing on science to direct the resources of nature with active compassion to meet the basic needs of all—especially the powerless, poor or otherwise marginalized (27)." This proposal, which the authors discuss having been taken up (ten years ago) in some form by schools across the continent, would be impossible without the space opened up by the emergence of engineering design as a central practice in the profession and educational establishment.

Dym acknowledged a growing recognition of the importance of design, and called for an acceleration of that process, pointing out an "attitudinal paradigm shift proposed...toward more explicit recognition of design as both the distinguishing feature of engineering practice and as a motivating factor in the learning of engineering" (146). Dym is describing a profession and practice that has in many meaningful ways acknowledged the pace of change in our world and has taken action to meet it. As Dym-like Geisler and Lewis, Mitcham, and others-makes clear, the ascendency of design in engineering education has opened the door for language, arts and the humanities to play a bigger role in engineering culture and practices, making 
the provocations of Design Unbound somewhat inevitable (though still much welcomed). If engineering education has migrated from, in Dym's terms, a primary focus on "analysis" to one that situates design as a "cornerstone" (146), it was only a matter of time before the ambiguity, creativity and imagination inherent in design would open the door to the kind of boundary crossing and transdisciplinary breadth celebrated and called for by Design Unbound. Indeed, Pendleton-Jullian and Brown exemplify this opening up when their book mashes together engineering, architecture, literature, art, philosophy, ecology, and more-and especially in their full-throated championing of the imagination.

I propose that we use the pandemic-altered semesters to further that project. We should not allow ourselves to become complacent in light of the restrictions imposed by COVID-19. If the world already resembled a white water rapid in 2018 (when Design Unbound was published), then it has only become more so now, and the need to encourage students to develop the imagination that us humans need to save this world has increased in turn. In this project, we, of course, depend utterly on the students themselves. As Pendleton-Jullian and Brown put it, "the suspension of disbelief required to act in this space of imagination can only be accomplished through the wonder of the student or designer" (1: 151).

Wonder! How quaint, how needed, how perpetually new.

\section{Toward Wonder and Imagination: The Case for Permanent Learning}

Now the summer has advanced such that instructor hiring and training is upon us. It is nearing the time when we must seriously consider what is plausible. We must consider the very real constraints upon our students and instructors, wherever they are reaching us from. Our students will be, typically, very busy. And now they are not allowed to see each other face-to-face. Our Teaching Assistants and Communication Instructors are in a similar situation, as are we all. We meet, now, on the internet (or at a distance outside), and while we must be thankful for the progress made by educational technology, we also must be able to correctly identify our limits.

There are other considerations as well. Students working in languages they are still mastering will be faced with the challenge to master that language while using that language to mediate collaborative creativity through the extra mediation of computers and the internet. Those are a lot of layers for one students' imagination to break through in order to achieve intersubjectivity. We should also be aware of visual and other modes of communication. While language is inevitably involved in the deployment of those modes, those modes themselves deserve a close examination in this current context. The same can be said for how mathematics discourse 
facilitates collaborative learning in design courses. In addition, students' personal circumstances will mediate what different courses and institutions will be able to do. We must also consider that engineering's inherent carefulness-something we must appreciate as we walk across any bridge that holds - will inevitably rebel to some extent against some kind of "worldchanging" ethos. After all, we need our engineers to master the details, and that seems so often to preclude such dreamy concepts as creativity, much less imagination.

Yet, I implore you, fellow human: what else are we going to do? As I write this sentence, the Siberian Arctic-not to mention the Amazon rainforest or California-continues to burn and a massive hurricane recently pummeled an already battered the Gulf coast. Meanwhile, COVID-19 continues to spread across the globe, including in the country-once-known-as-the-lone-superpower, where the pandemic has intensified underlying weaknesses and divisions, causing cultural, political, and even civilizational stability to come seriously into question, threatening further disorder on a global scale. Again, this is just a tiny slice of the challenges we face as a species on what is still our only planet to live on. If ever there was a time for the builders of our worldthat is, our engineers-to awaken their imaginations, this would seem to be a time when, really, it is too late for that. But, better late than never.

Finally, we should remember how much we can retain, and gain, during this emergency move online. There is not room here to elucidate specific, practical strategies for instructor and student training to optimize this move (though this needs to be, and is, in the works in so many ways), but we can say that language use in all its available modes remains essential to the attainment of the positive and productive intersubjectivity of student teams, and that that is essential to the learning we seek to engender. We can also say that training, and language training in particular, will be essential to the move online, given all the known challenges and anticipating the unknown. While we lose our natural facial expressions, body language, and everything else we use to transmit meaning face to face, we do still retain (many of us, at least) the ability to communicate in multiple ways online, often through language and texts.

That means we might write to each other more to make up for the face-toface. We might make more phone calls than before. That is, if we are lucky in this world. By that measure, the students we teach this year will also be lucky. It seems, then, that it is on us to make sure we do our best to make sure that is the truth. That means we have to do the best we can with what we have. Such goals can only be met through training. It is time to start training. Even if we do not yet know how exactly to train for this unprecedented time, we need to start so we can be better, as Hubbard and others suggest, at learning as teachers, so we can best deploy our imaginations in course design and 
deployment, and so that we can make the inevitably necessary on-the-fly adjustments to our course delivery.

\section{Next Steps: Designing, Delivering, and Training for a Resilient Fall 2020 Term Project}

If the above proves anything, it is that the Fall 2020 term will be unpredictable on multiple interconnected levels. While we should carefully consider the plethora of research that can guide us, we also must rush to complete our course designs, and given the novelty of our current circumstance, no past research will be sufficient to predict the course of the next school year. We do not know how student attitudes, aptitudes, and ability to engage in design tasks will be impacted by the pandemic. We do not know how instructors will respond to the new abnormal of online-only delivery. We also do not know the ways in which a potential fall project will interact with those, and other, uncertainties. The question becomes, then, how do you prepare for this? Leon Botstein, president of Bard College, compared course planning in the summer of 2020 to "driving through a dense fog," a circumstance in which "you go very slowly" (Alvarez). Yet, we are also pressed for time to get our courses together, suggesting that we need to master a paradox: how to go fast, but slowly.

To meet this challenge, I suggest that we will need a fall project and course design that has the following characteristics:

1. Flexibility for students in design focus and ambition, allowing them to adjust their approach to the project to fit their circumstances and allow them to engage with the course concepts and skills, as well as with each other (to form a sense of community within the course).

2. A course delivery structure that is attuned to changing information regarding student engagement and that can adjust accordingly (within reasonable limits).

3. A firm certainty that, despite the need for flexibility and adjustment, students will meaningfully engage with and learn the core principles of engineering design and communication and its attendant processes, especially those to do with teamwork, collaboration and the traditional emphasis on hands-on design experience.

4. A well-trained frontline instructor corps that can guide students with a balance of firm authority and support, but also openness, empathy and understanding. Instructors also provide a layer of organization linking students to the course.

5. A reflexive, resilient course structure that allows for the adjustability suggested above, but that also keeps a close eye on student, instructor and staff mental health, stress, and workload. 
A fall project and course design that follows these principles would have several advantages. First, it would give agency to students, empowering them to play a role in resolving the uncertainties and ambiguities that will almost inevitably arise. The promotion of such agency supports the general goal within engineering design education to equip students to meet uncertainty and ambiguity through design. A course design that can make reasonable adjustments to meet unforeseen challenges or opportunities while maintaining core learning objectives would provide students with enough structure to avoid feeling lost, but not so much structure that the students feel over-constrained and lose the motivation that so often goes along with increased student agency. Meanwhile, instructors who have been trained in the affordances of online teaching and facilitation can provide the needed structure for community and rapport to thrive among their student teams, while providing links between individual students, teams and the course as a whole. Finally, a system that allows for regular check-ins and facilitates feedback will inform course coordinators of issues concerning workloads at different levels of the course, to ensure that the course's flexibility does not translate to an undue burdening of any course participants.

\section{Conclusion}

The 2020 Fall Term promises to be complex and difficult. Without a doubt, we will need our imaginations to be working in our favour, as will our students, and as will the entire world. We should also remember, though, that we can and should take concrete steps to prepare to make the best use of our imagination and creativity in order to meet the enormous challenges that await us. 


\section{Works Cited}

Alvarez, Maximillian and Gutkin, Len. "Planning for the Fall is Like 'Driving Through a Dense Fog.'" The Chronicle of Higher Education. April 29, 2020. https://www.chronicle.com/article/planning-for-the-fall-is-like-drivingthrough-a-dense-fog/

Bhagwatwar, Akshay \& Massey, Anne \& Dennis, Alan. "Contextual Priming and the Design of 3D Virtual Environments to Improve Group Ideation." Information Systems Research, 29, (2017). DOI: 10.1287/isre.2017.0721.

Bettoni, Marco \& Bernhard, Willi \& Bittel, Nicole. "Collaborative Creativity with eCiC." Procedia Social and Behavioral Sciences, 174, (2014). DOI: 10.1016/j. sbspro.2015.01.1135.

Borunda, Alejandra "What a 100-degree Day in Siberia Really Means." June 23, 2020. Nationalgeographic.com. https://www.nationalgeographic.com/ science/2020/06/what-100-degree-day-siberia-means-climate-change/\#close

Brookfield, S.D. Becoming a Critically Reflective Teacher. San Francisco: Jossey-Bass: 1995.

Dolce, Chris. "Hurricane Season has Just Begun, but We've Already Seen 5 Unusual Things Happen." 10 June, 2020. https://weather.com/safety/hurricane/ news/2020-06-10-2020-hurricane-season-unusual-start

Dym, C.L. "Learning Engineering: Design, Languages, and Experiences." Journal of Engineering Education, 88 (1999): 145-148. doi:10.1002/j.2168-9830.1999.tb00425.x

Ez-zaouia, Mohamed; Tabard, Aurélien, Lavoué, Élise. "Emodash: A dashboard supporting Retrospective Awareness of Emotions in Online Learning." International Journal of Human-Computer Studies, Vol. 139, (2020): 102411. DOI: 10.1016/j.ijhcs.2020.102411

Goldman, Steven L "The Social Captivity of Engineering." In Durbin, Paul T., (Ed.). Critical Perspectives on Nonacademic Science and Engineering. Bethlehem: Lehigh UP, 1991: 121-45.

Geisler, Cheryl \& Lewis, Barbara. "Remaking the World Through Talk and Text: What We Should Learn from How Engineers use Language to Design." In Horowitz, R. (Ed.). Talking Texts. New York: Routledge, (2007). https://doi. org/10.4324/9781315087450

Haines, K. J. "Learning to Identify and Actualize Affordances in a New Tool." 
Language Learning \& Technology, 19(1) (2015): 165-180. https://www.lltjournal. org/item/2893

Hubbard, P. \& Ioannou-Georgiou, S. "An Introduction to Teaching Reflectively with Technology." (2018) IATEFL. https://web.stanford.edu/ efs/tert/TERT.pdf

Hubbard, P. "Making a Case for Learner Training in Technology Enhanced Language Learning Environments." CALICO Journal, 30(2), (2013):163-178.

Johnston, Stephen; Lee, Alison \& McGregor, Helen "Engineering as Captive Discourse." Philosophy \& Technology. 1:3-4 Spring (1996):128-136.

Lai, C. \& Li, G. "Technology and Task-Based Language Teaching: A Critical Review." CALICO Journal, 28(2), (2011): 498-521.

Lopata, Joel \& Nowicki, Elizabeth \& Joanisse, Marc. "Creativity as a Distinct Trainable Mental State: An EEG Study of Musical Improvisation." Neuropsychologia, 99 (2017).10.1016/j.neuropsychologia.2017.03.020.

Link, Georg \& Siemon, Dominik \& de Vreede, Gert-Jan \& Robra-Bissantz, Susanne. "Evaluating Anchored Discussion to Foster Creativity in Online Collaboration." Collaboration and Technology [electronic resource]: 27st International Conference, CRIWG 2015, Yerevan, Armenia, September 22-25, 2015, Proceedings (eds. Baloian, N.; Zorian, Y.; Taslakian, P.; Shoukouryan, S.) (2015). 10.1007/978-3-319-22747-4.

Lindsay, Euan (Senior Lecturer); Munt, Roger; Rogers, Helen; Scott, David \& Sullivan, Karen "Making Students Engineers." Engineering Education, 3:2, (2008): 28-36.

Koschmann, T. D. "Paradigm Shifts and Instructional Technology: An Introduction." CSCL: theory and practice of an emerging paradigm. L. Erlbaum Associates: 1996.

Krasny, Karen. "Toward an Embodied Account of Double-Voiced Discourse: The Critical Role of Imagery and Affect in Bakhtin's Dialogic Imagination." Semiotica, Issue 213 (2016). DOI: 10.1515/sem-2016-0159.

Mitcham, Carl "The True Grand Challenge for Engineering: Self-Knowledge." Issues in Science and Technology. 31:1, (2014): 19-22.

Mitcham, Carl \& Muñoz, David Humanitarian Engineering. Morgan Claypool, 2010.

Perez, Carlota. "Technological Revolutions and Techno-Economic Paradigm

Online Ahead of Print | University of Toronto Quarterly | Special Issue on The Creative Humanities https://source.sheridancollege.ca/fhass_creative_humanities/5 
Shifts." Cambridge Journal of Economics, 34(1), (2010): 185-202. DOI:10.1093/ cje/bep051

Reinders, H. \& White, C. "20 Years of Autonomy and Technology: How Far Have We Come and Where to Next?" Language Learning \& Technology, 20(2), (2016): 143-154. https://www.Iltjournal.org/item/2952

Rovai, Alfred. "Building Sense of Community at a Distance." International Review of Research in Open and Distance Learning. 3(1), (2002): 1-16.

Rush, S. Craig, Wheeler, Joanna \& Partridge, Ashley. "A Proposed Template for an Emergency Online School." Professional Training Curriculum Contemporary School Psychology.18: (2014): 143-156. DOI 10.1007/s40688-0140015-9

Rush, S. Craig, Wheeler, Joanna \& Partridge, Ashley. "Implementing Emergency Online Schools on the Fly as a Means of Responding to School Closures after Disaster Strikes." Journal of Educational Technology Systems 2016, 45(2) (2016): 188-201.

Pendleton-Jullian, A. M., Brown. Design Unbound: Designing for Emergence in a White Water World: Volumess 7-2. MIT Press. 2018.

Schwartz, D.L. "The Emergence of Abstract Dyad representations in Dyad Problem Solving." The Journal of the Learning Sciences. 4 (3) (1995): 321-354.

Senior, R. "Connectivity: A Framework for Understanding Effective Language Teaching in Face-to-Face and Online Learning Communities." RELC Journal, 41(2), (2010): 137-147.

Stahl, G., Koschmann, T., \& Suthers, D. "Computer-Supported Collaborative Learning: An Historical Perspective." In R. K. Sawyer (Ed.), Cambridge Handbook of the Learning Sciences, revised version. Cambridge University Press, (2014): 479-500). Web: http://GerryStahl.net/pub/chls2.pdf.

Stahl, G. "From Intersubjectivity to Group Cognition." Computer Supported Cooperative Work (CSCW). 25(4), (2016): 355-384. Web: http://GerryStahl.net/ pub/intersubjectivity.pdf. Doi: 10.1007/s10606-016-9243-z.

Voigt, Matthias \& Bergener, Katrin. "Enhancing Creativity in Groups Proposition of an Integrated Framework for Designing Group Creativity Support Systems." Proceedings of the Annual Hawaii International Conference on System Sciences. (2013) 10.1109/HICSS.2013.195. 